\title{
Planejamento agroturístico de propriedade rural sob a perspectiva da conservação ambiental ${ }^{1}$
}

\author{
Bernadete da C. C. G. Pedreira ${ }^{2}$, Rozely F. dos Santos ${ }^{3}$ \& Jansle V. da Rocha ${ }^{4}$
}

\begin{abstract}
RESUMO
Apesar de recente no Brasil, o agroturismo se vem expandindo como um meio promotor de desenvolvimento rural, de aumento da renda dos pequenos produtores rurais e da conservação dos recursos naturais, culturais e paisagísticos de espaços agrários, mas há fal ta de planejamento adequado da atividade em relação ao meio ambiente e orientação aos proprietários rurais, que tem interesse em desenvolvê-lo. Neste estudo se propõe avaliar indicadores e apresentar uma estratégia metodológica que possa qualificar o potencial agroturístico de uma propriedade rural e impactos, pela integração de premissas de conservação e de planejamento ambiental. Como estudo de caso foi selecionada a Fazenda Fartura, em Socorro, SP, município situado em região turística mas que apresenta alto potencial natural de risco de erosão do solo. Indicadores foram avaliados para agricultura e pecuária, para conservação dos elementos naturais, para o turismo e para a infraestrutura física e social; cujos resultados obtidos apontaram as limitações e potencialidades da propriedade rural para o desenvolvimento do agroturismo e da estratégia apresentada.
\end{abstract}

Palavras-chave: agroturismo, indicadores, potencialidade

\section{Agro-touristic planning of rural property under the perspective of the environmental conservation}

\begin{abstract}
Agro-tourism is recent in Brazil, but is growing as a means of promoting agricultural development, to increase the income of small rural producers and the preservation of natural resources, and of cultural and agricultural landscape aspects. However, there is lack of adequate planning of the activity regarding the environment and orientation to the farmers who have interest in developing it. Thus, this study proposes to evaluate indicators and to present a methodological strategy that can qualify the agro-tourism potential of the farm and impacts by integration of premises of conservation and environmental planning. As a case study the Fazenda Fartura, located in Socorro, SP, was selected. This city is part of the touristic region, but has a high natural potential risk for soil erosion. Indicators were evaluated for the agriculture and cattle raising, conservation, tourism and for the physical and social infrastructure. The results obtained point out the restrictions and potentialities of the farm for the agro-tourism development, as well as of the presented strategy.
\end{abstract}

Key words: agro-tourism, indicators, potentiality

\footnotetext{
1 Parte da Tese de Doutorado da primeira autora, defendida na Faculdade de Engenharia Agrícola da UNICAMP, Campinas, SP

2 Embrapa Solos. Ruajardim Botânico, 1024, Jardim Botânico, CEP 22460-000, Rio de Janeiro, RJ. Fone: (21) 2179-4562. Fax: (21) 2274-5291. E-mail: pedreira@cnps.embrapa.br 3 FEC/U NICAM P. Cidade U niversitária "Zeferino Vaz", s/n, Distrito de Barão Geraldo, CP 6011, CEP 13083-875, Campinas, SP. Fone: (19) 3521-2353. Fax: (19) 3521-2411. E-mail: roze@fec.unicamp.br

4 FEAGRI/U NICAM P. Fone: (19) 3521-1007. Fax: (19) 3521-1064. E-mail: jansle.rocha@agr.unicamp.br
} 


\section{INTRODUÇÃO}

O espaço rural vem deixando de ser considerado como local propício exclusivamente às atividades agropecuárias ou extrativistas. Perspectivas de geração de novas oportunidades de negócios em nichos nascentes, como o turismo e o lazer, mostram-se promissoras e atraentes aos proprietários rurais (Ferrão, 2007).

A diversificação do setor primário e o surgimento de atividades e serviços não agrícolas no meio rural, ocupam cada vez mais destaque no cenário produtivo de amplas regiões, gerando motivação para investimentos privados e apoios governamentais, além de despertarem grande interesse por parte dos empreendedores do campo (Salvati, 2003). Entre essas novas atividades, destacam-se o turismo rural e o agroturismo.

A Associazione Italiana Per L'Agricoltura Biologica define o agroturismo como sendo toda atividade de hospitalidade praticada por produtores rurais através da utilização de suas próprias fazendas, em conexão e de forma complementar às atividades agrícolas, silviculturais e de criação, as quais permanecem como atividades principais (AIAB, 2000).

Como salientado por Cox \& Fox (2003), a relação entre a agricultura e o turismo nas economias rurais deve ser analisada de forma a garantir que o potencial da agricultura como geradora de atividades de lazer possa ser explorado. Kuo \& Chiu (2006), consideram essa relação que se estabelece no agroturismo como sendo um elemento-chave para o desenvolvimento do turismo responsável sob os aspectos social e ambiental nas zonas rurais. Além disso, a atividade oferece novas oportunidades de renda para as populações rurais, incentivando a expressão cultural sob a forma de intercâmbio de práticas agrícolas, de patrimônio artístico, de artesanato e tradições culinárias do meio rural. Entretanto, existem características ambientais particulares em cada espaço, independentemente da escala de trabalho ou de seus limites físicos, gerando a necessidade de se incorporar o planejamento e a gestão do espaço de modo que as atividades produtivas degradem minimamente o meio ambiente e que os recursos naturais possam ser utilizados de modo sustentável (Campanhola \& Silva, 2000). Para que as atividades de turismo promovam o desenvolvimento do espaço rural e sirvam como elemento complementar para outras atividades de caráter tradicional como: além da agricultura, a pecuária, o artesanato, a pequena indústria entre outras, é necessário que se adotem critérios de sustentabilidade para garantir a continuidade da atividade aliada à conservação dos recursos naturais existentes (Vezzani, 2008); portanto, o turismo rural e o agroturismo requerem um planejamento adequado e que deve envolver, além do diagnóstico, as alternativas de minimização dos impactos ambientais negativos e a transformação das ameaças de degradação ambiental em oportunidades de agregação de valor à propriedade rural (Santos \& Gomes, 2003). Tal incremento do potencial econômico sustentável das paisagens rurais exige a cooperação e a parceria entre a comunidade rural e o uso produtivo sustentável dos recursos rurais (Oliver \& Jenkins, 2003). Também é necessário considerar uma avaliação das potencialidades dos recursos naturais, os padrões de ocupação e uso da terra e as possíveis transformações resultantes da exploração turística. As atividades turísticas e infraestruturas devem ser localizadas em áreas bem selecionadas, de forma a evitar impactos e limitar o seu desenvolvimento em regiões vulneráveis (AIAB, 2000); além disso, devem ser respeitadas a dimensão, a natureza, o caráter e a capacidade de absorção do meio ambiente natural e social da área escolhida, conservando-se os recursos naturais, a paisagem, os recursos históricos, arqueológicos e a sua identidade cultural.

É preciso considerar que as prerrogativas teóricas aqui expostas só serão viabilizadas se o diagnóstico do meio e a condução da estratégia para tomada de decisão estiverem fundamentados sobre uma base sólida de indicadores que representem esse contexto. Os indicadores devem responder sobre as possibilidades de exploração dos recursos sem prejuízos da sua conservação, em cuja direção este trabalho defende a idéia de que há, pelo menos, três grupos de indicadores a serem considerados em um diagnóstico que visa à seleção de propriedade rural para o agroturismo: potencialidade agropecuária, qualidade do meio natural e de atributos turísticos. Como identificar e selecionar os principais parâmetros desses três grupos? Os grupos são suficientemente representativos? Existe diferença de importância entre os grupos para tomada de decisão? Como sobrepor informações de tantas naturezas sem perder o enfoque do agroturismo? Para responder a essas questões se objetivou, no presente estudo, estruturar uma base metodológica para levantar, selecionar, hierarquizar e manejar um conjunto de indicadores que pudessem apontar as limitações e potencialidades de uma propriedade rural frente à possibilidade de se instalar atividades agroturísticas.

O estudo de caso selecionado foi a Fazenda Fartura, situada no município de Socorro, integrante da região "Circuito Paulista das Águas”. Apesar da riqueza em atributos que podem ser aproveitados para o agroturismo, esta região apresenta altos riscos de erosão e perda de solos devido à alta intensidade de uso da terra e ao manejo agrícola inadequado (Rocha et al., 2000). Se bem conduzida, a exploração do agroturismo poderá ser uma boa alternativa econômica para os empreendedores rurais aí estabelecidos e, ao mesmo tempo, contribuir para minimizar os efeitos negativos da sobreutilização da terra para a produção e geração de renda.

\section{MATERIAL E MÉTODOS}

A estrutura metodológica utilizada neste estudo incluiu as quatro etapas descritas a seguir.

\section{Seleção e ponderação dos indicadores}

Os indicadores foram selecionados em virtude de constituírem o nível básico da informação necessária para administrar o agroturismo de forma sustentável. Com esta premissa, a decisão sobre os indicadores a serem utilizados foi baseada em exaustivo levantamento bibliográfico em relação aos parâmetros que pudessem melhor indicar e/ou relacionar 
fatores de importância agroturística existentes e potenciais de um espaço rural (associados aos fatores de qualidade agrossilvopastoril, ambiental, turístico e de infraestrutura física e social) e de conservação ambiental.

Inicialmente se adotou, para a avaliação dos indicadores, a sua separação em três conjuntos agrupando-se em blocos, os parâmetros de qualidade ambiental, os parâmetros de potencialidade agrossilvopastoril e os parâmetros de potencialidade turística. Foram atribuídos critérios de ponderação em função da caracterização, da ênfase ou dos limites dados às informações descritas na literatura para cada indicador, conforme Tabelas 1 a 3 .

Tabela 1. Relação de indicadores agropecuários e os critérios para a sua ponderação

\begin{tabular}{|c|c|c|c|c|c|}
\hline Indicadores agropecuánios & Critérios ocorrência & pontos & critérios relativos à presença & & pontos \\
\hline \multirow[t]{4}{*}{ categorias agroturísticas } & presença & 3 & $\begin{array}{l}\text { entretenimentos associados a: agricultura, pecuária, } \\
\text { cobertura vegetal, silvicultura, lazer, recreação, esporte, } \\
\text { recepção, vias de acesso e circulação interna, patrimônio } \\
\text { histórico e cultural e água }\end{array}$ & 1 a 2 categorias & 1 \\
\hline & & & & 3 a 6 categorias & 2 \\
\hline & & & & $>6$ categorias & 3 \\
\hline & ausência & 1 & & & \\
\hline \multirow[t]{4}{*}{$\begin{array}{l}\text { diversidade de explorações } \\
\text { agrossilvopastoris de interesse agroturístico } \\
\text { com boas práticas de manejo e } \\
\text { conservação }\end{array}$} & presença & 3 & $\begin{array}{l}\text { café, cana, milho, horta, pomar/fruttferas, gado bovino, } \\
\text { outras criações, reflorestamamento de eucalipto, plantio em } \\
\text { nível, rotação de culturas, adubação, calagem, tratos } \\
\text { fitossanitários, capina, manejo do gado, uso de máquinas } \\
\text { agrícolas, irrigação, platio consorciado, controle biológico } \\
\text { de pragas }\end{array}$ & 1 a 2 critérios & 2 \\
\hline & & & & 3 a 5 critérios & 3 \\
\hline & & & & $>5$ critérios & 4 \\
\hline & ausência & 1 & & & \\
\hline \multirow[t]{4}{*}{ variações sazonais } & presença & 3 & $\begin{array}{l}\text { agrícolas (plantio, floração, frutificação, colheita, tratos } \\
\text { culturais, corte seletivo) }\end{array}$ & 1 a 2 critérios & 1 \\
\hline & & & & 3 a 4 critérios & 2 \\
\hline & & & & $>4$ critérios & 3 \\
\hline & ausência & 1 & & & \\
\hline \multirow[t]{4}{*}{ conflitos de uso da terra } & presença & 1 & conflitos entre uso atual e a capacidade de uso da terra & $\begin{array}{l}\text { até } 20 \% \text { da área total da } \\
\text { propriedade }\end{array}$ & 3 \\
\hline & & & & $\begin{array}{l}>20 \% \text { a } 50 \% \text { da área da } \\
\text { propriedade }\end{array}$ & 2 \\
\hline & & & & $\begin{array}{l}>50 \% \text { da área total da } \\
\text { propriedade }\end{array}$ & 1 \\
\hline & ausência & 3 & & & \\
\hline
\end{tabular}

Tabela 2. Relação de indicadores ambientais e os critérios para a sua ponderação

\begin{tabular}{|c|c|c|c|c|c|}
\hline Indicadores ambientais & Critérios ocorrência & pontos & critérios relativos à presença & & pontos \\
\hline \multirow[t]{3}{*}{$\begin{array}{l}\text { cobertura vegetal naturalidade estado de } \\
\text { preservação ou alteração }\end{array}$} & presença & 3 & $\begin{array}{l}\text { sinais de alteração (fogo, clareira, tocos, lixo, } \\
\text { desmatamento) }\end{array}$ & $\begin{array}{c}3 \text { critérios ou } 1 \text { critério em } \\
\text { grande extensão (muito } \\
\text { alterado) }\end{array}$ & 1 \\
\hline & & & & $\begin{array}{c}2 \text { a } 3 \text { critérios medianamente } \\
\text { alterado }\end{array}$ & 2 \\
\hline & & & & 1 critério pouco alterado & 3 \\
\hline \multirow[t]{3}{*}{ declividade } & & & & 0 a $6 \%$ & 3 \\
\hline & & & & $>6 \%$ a $25 \%$ & 2 \\
\hline & & & & $>25 \%$ & 1 \\
\hline \multirow[t]{3}{*}{ recursos hídricos } & natural & 3 & $\begin{array}{l}\text { rios, lagos, açudes, quedas dágua, fonte, nascente, } \\
\text { represa. canal }\end{array}$ & 1 a 2 & 1 \\
\hline & artificial & 2 & & 3 a 5 & 2 \\
\hline & & & & $>5$ & 3 \\
\hline \multirow[t]{2}{*}{ piscosidade } & presença & 3 & & & \\
\hline & ausência & 1 & & & \\
\hline \multirow[t]{2}{*}{ balneabilidade } & presença & 3 & & & \\
\hline & ausência & 1 & & & \\
\hline \multirow[t]{3}{*}{ densidade de drenagem } & baixa & 1 & & & \\
\hline & média & 2 & & & \\
\hline & alta & 3 & & & \\
\hline \multirow[t]{4}{*}{ fauna silvestre } & presença & 3 & espécies que oferecem perigo ao ser humano & 1 critério & 1 \\
\hline & & & refúgios & 1 critério & 2 \\
\hline & & & pousio aves / rotas migratórias espécies raras / ameaçadas & 1 critério ou mais & 3 \\
\hline & ausência & 1 & & & \\
\hline
\end{tabular}


Tabela 3. Relação de indicadores turísticos e os critérios para a sua ponderação

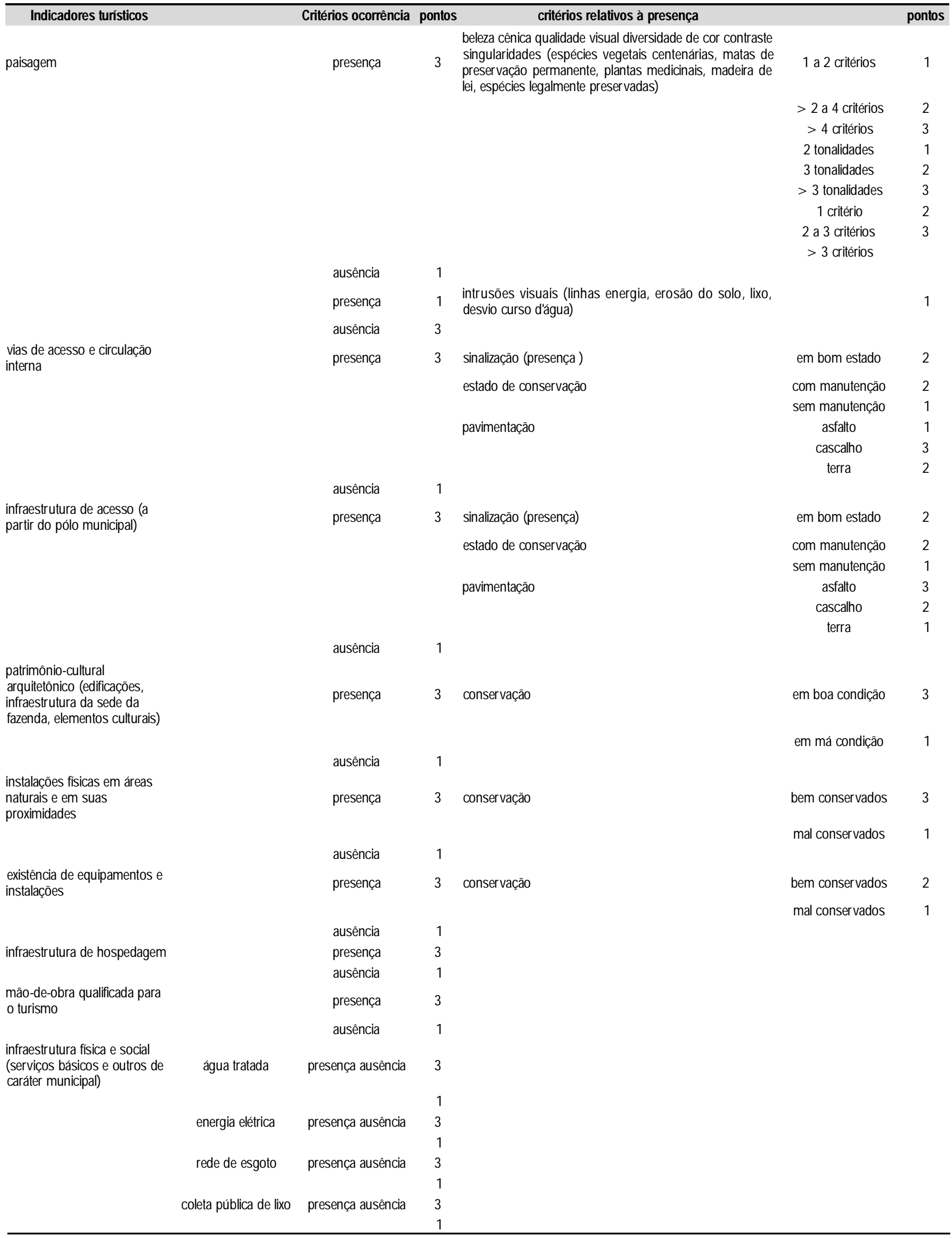


Continuação...

$\begin{array}{ccc}\text { telefonia } & \text { presença ausência } & 3 \\ & & 1 \\ \text { reciclagem } & \text { presença ausência } & 3 \\ & & 1 \\ \text { correios } & \text { presença ausência } & 3 \\ & & 1 \\ \text { internet } & \text { presença ausência } & 3 \\ & & 1 \\ \text { rádio / TV } & \text { presença ausência } & 3 \\ & & 1 \\ \text { telefones / fax } & \text { presença ausência } & 3 \\ & & 1 \\ \text { transporte } & \text { presença ausência } & 3 \\ & & 1 \\ \text { Assistência de } & & \text { presença } \\ \text { serviços e distância } & 3 \\ \text { relativa } & & \end{array}$

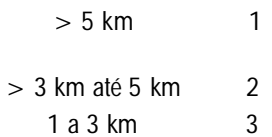

ausência

1

Os atributos utilizados como parâmetros indicadores da qualidade visual da paisagem foram baseados em estudos de Pires (2001)

No processo de pontuação se consideraram as propriedades: quantidade (quanto maior a quantidade do atributo positivo, maior a pontuação) para alguns dos indicadores e, para outros, a qualidade (quanto maior a importância do atributo positivo, maior a pontuação). Alguns parâmetros ambientais respondem por mais de um critério, desta forma, por exemplo, a cobertura vegetal natural obtinha maior pontuação (naturalidade, estado de conservação, interferências antrópicas e assim por diante).

\section{Seleção da propriedade rural}

Conforme descrito em Pedreira (2006), a seleção das melhores fazendas para agroturismo deve ser precedida pela determinação da área de maior potencial agroturístico dentro da região de interesse para esta atividade. Referida área foi escolhida dentro do município de Socorro, de acordo com os seguintes critérios: existência efetiva de uso agrícola e/ou silvopastoril, existência de características com potencialidade turística e a vizinhança com outras áreas igualmente bem qualificadas, proximidade do centro urbano e a oferta de serviços e a inexistência ou menor extensão ocupada com áreas de uso restrito, em que as últimas se referem às áreas que apresentam fragilidade ambiental e/ou restrição de uso de ordem legal (proximidade da rede viária, em torno das nascentes, áreas ribeirinhas, topo de morros, em torno de lagos e lagoas naturais ou artificiais, encostas com declividade superior a $45^{\circ} \mathrm{e}$ várzeas de rio sujeitas a alagamentos).

Dentro dessa área de alto potencial foram localizadas, visitadas e comparadas, cinco propriedades rurais dentre elas a Fazenda Fartura, que foi selecionada porque respondia melhor aos critérios: menor extensão de áreas de restrição ambiental, maior diversidade de fontes de exploração agroturística, maior facilidade de acesso, localização estratégica (que possibilita o papel de elo de ligação entre outras propriedades de alto potencial, facilitando o circuito agroturístico) e vontade dos proprietários no desenvolvimento da atividade. A fazenda ocupa uma área aproximada de 440 ha e sua localização é apresentada na Figura 1.

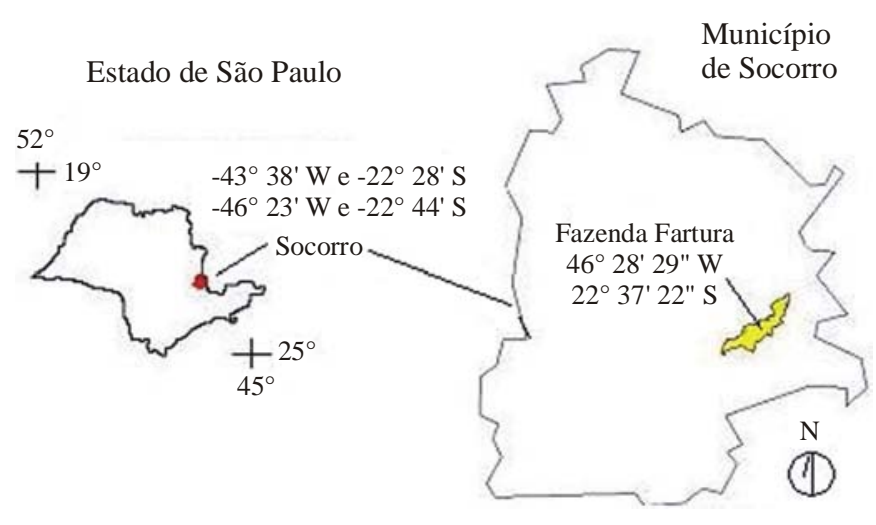

Figura 1. Local ização da Fazenda Fartura no município de Socorro, SP

\section{Aplicação dos critérios no estudo de caso}

O levantamento de dados e de informações em nível local, foi realizado através de visitas de campo, no período entre agosto/2005 e janeiro/2006, entrevistas estruturadas com os proprietários, consultas à Casa de Agricultura e às agências de turismo de Socorro, interpretação de fotos aéreas, uso de GPS para georreferenciamento de dados pontuais e compilação de dados secundários analógicos e digitais.

O mapeamento do uso da terra, da cobertura vegetal, de vias de circulação interna da propriedade rural e de redes de infraestrutura, foi realizado por meio de interpretação visual de fotografias aéreas digitais do município de Socorro, na escala original de 1:30.000, voo Base Aerofotogrametria S/A, ano 2000, trabalhadas em software ENVI.

Os dados mapeados foram plotados sobre cartas planialtimétricas e de drenagem realizadas pelo IGC, ano 1979, que recobrem parte do município de Socorro (Folhas SF-23-YB-IV-1-NO-E, SF-23-Y-A-VI-2-NE-D, SF-23-Y-B-IV-1-SOA, SF-23-Y-A-VI-2-SE-B e SF-23-Y-A-VI-2-NE-F), reduzidas à escala de mapeamento (escala original de 1:10.000).

O mapeamento das classes de declive associadas ao relevo, foi feito a partir do Modelo Digital do Terreno (MDT), gerado no software IDRISI Kilimanjaro, pela interpolação das 
curvas de nível com eqüidistância de $5 \mathrm{~m}$, digitalizadas em software AUTOCAD versão 2004. Para obtenção do mapeamento das áreas de conflito de uso agrícola e que representam as fragilidades ambientais da propriedade rural, realizou-se primeiro o recorte do mapa de classes de capacidade de uso da terra do município de Socorro, elaborado por Rocha et al. (2000), em escala 1:50.000 que, por sua vez, foi elaborado com base na classificação descrita em Lepsch (2002); este mapa foi, então, cruzado com o mapa de uso da terra e cobertura vegetal.

Para o mapeamento de atributos lineares ou pontuais (nascentes, impactos) realizou-se buffer (análise radiocêntrica), gerando uma zona em torno do atributo e possibilitando sua visualização espacial na escala de estudo; realizou-se ainda, um levantamento dos principais impactos ou ações impactantes observados na propriedade rural, tomando-se por base uma listagem compilada da literatura sobre agroturismo; as demais informações foram obtidas pelas entrevistas estruturadas e, sempre que possível, confirmadas em levantamentos de campo.

\section{Elaboração do diagnóstico e tomada de decisão}

Realizou-se a avaliação do potencial agroturístico da propriedade rural por meio da valoração e somatória da pontuação exponencial atribuída a cada um dos 3 grupos de atributos locais (ambientais, agropecuários e turísticos), levantados em inventário e cruzados entre mapas. Como exemplo para o atributo patrimônio histórico-cultural a presença recebeu pontuação maior (3) em relação à ausência (1) e, de acordo com o maior ou menor número de critérios atendidos propícios ao agroturismo, recebia expoentes maior ou menor, respectivamente; este caminho metodológico permitiu identificar a potencialidade predominante da propriedade (grupo de atributo) e os atributos de maior peso no processo de decisão sobre a atividade agroturística.

\section{RESULTADOS E DISCUSSÃO}

De acordo com os levantamentos efetuados pode-se afirmar que um dos principais aspectos da Fazenda Fartura é ela exprimir a importância e o retrato da arquitetura do ciclo do café do final do século XIX, com cerca de 30 edificações, equipamentos originais, histórias originais e sede de festas, como de Santo Expedito; esta unidade agropecuária (30\% agricultura, $40 \%$ pecuária e $30 \%$ silvicultura, produção de mel e turismo) é do tipo familiar e as atividades de turismo são uma fonte complementar, inferior a $10 \%$ do total de renda. O questionário estruturado evidenciou que as atividades turísticas hoje existentes são informais e os funcionários não tem treinamento para tratar o agroturismo. Segundo a visão do proprietário, os principais impedimentos para tal atividade dizem respeito à falta de incentivo, rigidez da legislação, ao melhor rendimento com uso de máquinas ao invés de funcionários e dificuldades de comercialização dos produtos.

Em relação ao aspecto físico-biótico, a fazenda tem solos do tipo Argissolo exigindo, algumas vezes, calagem e adubação. Quanto à cobertura vegetal natural observa-se que as áreas com matas (Figura 2A) estão sobre relevos íngremes, sujeitos a erosão; na propriedade a faixa de declividade está entre 12 a 43\% (Figura 2B e C), com predomínio de campos para a pecuária. As avaliações de campo permitem dizer que as suas atividades de turismo não tiveram influência nas mudanças de uso da terra ocorridas entre

A.

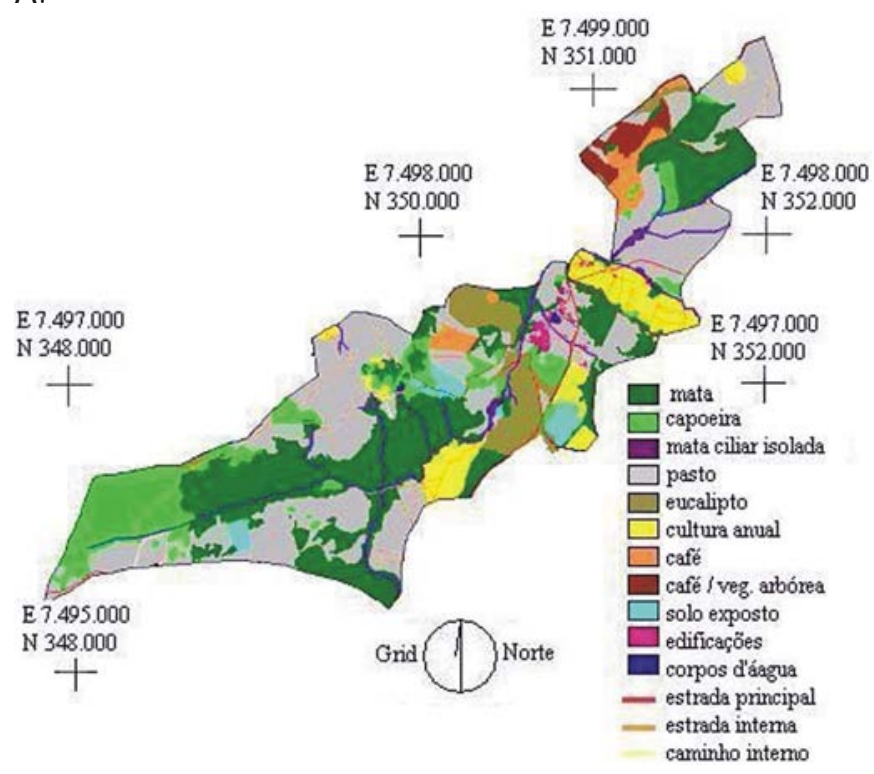

B.

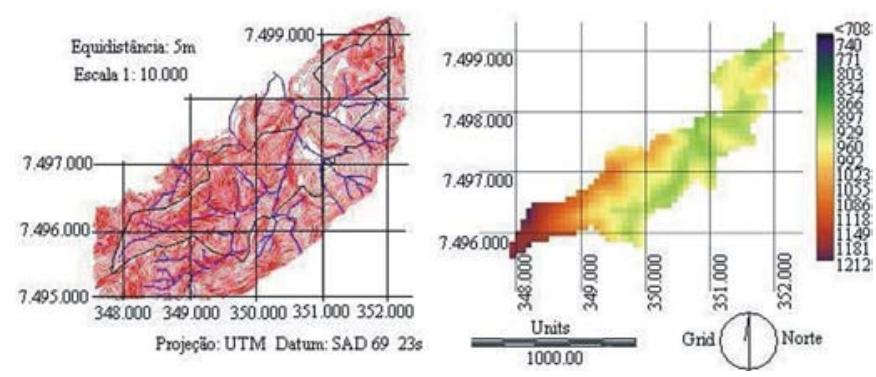

C.

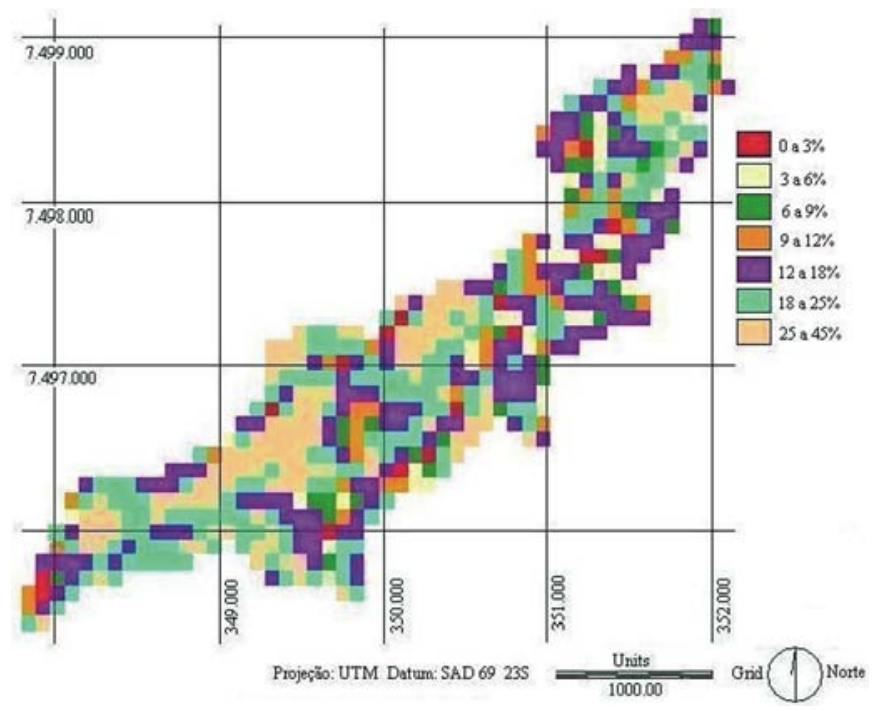

Figura 2. Mapeamento do uso e cobertura da terra, dados de 2000 e 2006 (A), altimetria e correspondente MDT (B) e declividade (C) da Fazenda Fartura 
2001 e 2006. A disponibilidade hídrica é alta, com propriedades terapêuticas, dois lagos e pequenas quedas d'água porém 15 das 31 nascentes que compõem a microbacia hidrográfica local estão fora dos limites da propriedade; nela se encontram espécies animais de pequeno e médio porte e os raros acidentes registrados com visitantes são com cascavel, abelhas e vespas porém as visitas de 5 a 730 pessoas são guiadas e dispõem de atendimento de primeiros socorros. Existe diversidade de criação animal (como gado holandês, guzerá e nelore, carneiros, galinhas, abelhas) e cultivos (Figura 2A) como cana, milho, mandioca, batata-doce e feijão; há sazonalidade nas atividades rurais e predomínio da classe VI, ou seja, terras aptas para pastagem extensiva ou vida silvestre; em suma, é notória a potencialidade para o desenvolvimento do agroturismo e atividades correlatas, mas as características biofísicas levam à recomendação de cuidados para o manejo. A Tabela 4 apresenta a área em hectares das diferentes categorias de uso e cobertura da terra da Fazenda Fartura.

Tabela 4. Extensão, em área, das categorias de uso e cobertura da terra (2000)

\begin{tabular}{lr}
\hline Categorias & Área (ha) \\
Mata & 121,00 \\
Capoeira & 56,80 \\
Mata ciliar isolada & 1,80 \\
Café & 14,40 \\
Cultura anual & 29,20 \\
Eucalipto & 29,00 \\
Pasto & 143,00 \\
Solo exposto & 12,97 \\
Corpos d'água & 29,90 \\
Edificações & 2,20 \\
Total & 440,27 \\
\hline
\end{tabular}

A sobreposição entre o mapa de uso e cobertura atual (Figura 2A) e mapa de capacidade de uso do solo da Fazenda Fartura (Figura 3A), devidamente ponderados, resultou na elaboração do mapa de adequação de uso da terra da propriedade, apontando onde existem as áreas de conflito e de maior fragilidade ambiental (Figura 3B).

A análise deste mapa mostrou que a inadequação de uso da terra na propriedade ocorre em cerca de $15 \%$ da sua área total devido, principalmente, aos cultivos anuais. Como na propriedade não há terrenos com classes de capacidade de uso que comportem cultivos anuais, todas as áreas ocupadas com esse tipo de exploração representam conflitos de uso da terra. Para um programa de agroturismo, que prepondera a mensagem educacional positiva e não negativa, o primeiro passo seria solucionar essas desconformidades.

Pelo lado positivo e se considerando que em cerca de $85 \%$ da área total da fazenda a terra se mostrou adequada quanto à sua capacidade de uso, ficou evidenciada uma ocupação do espaço rural em alta conformidade com sua vocação de uso, com trilhas para jovens e adultos $(3,9 \mathrm{~km}$, declividades de 10 a $20 \%$ ) que cortam remanescentes florestais, eucaliptal, pastagem e outros elementos passíveis de se integrarem aos atrativos agroturísticos. Inversamente, as condições de infraestrutura de hospedagem não existem ou são precárias, havendo somente recepção sem pernoite, além da falta de sinalização interna adequada para tais atividades; tem

A.

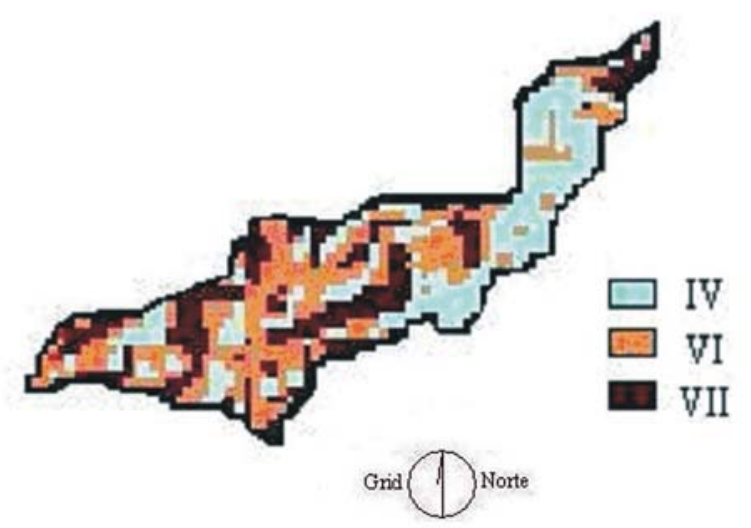

Projeção: UTM Datum: SAD69 23s

Fonte: Rocha et al. (2000), modificado

B.

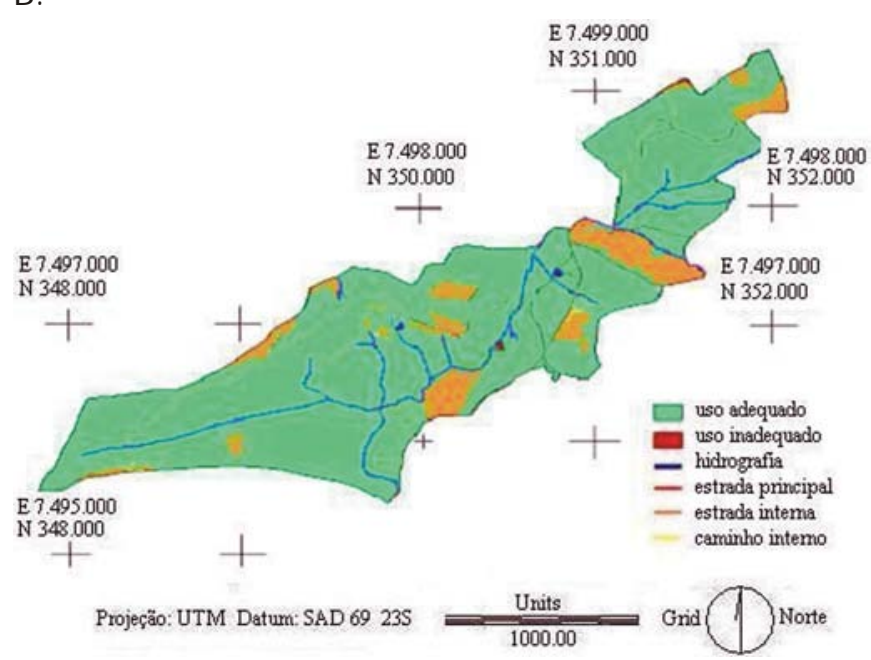

C.

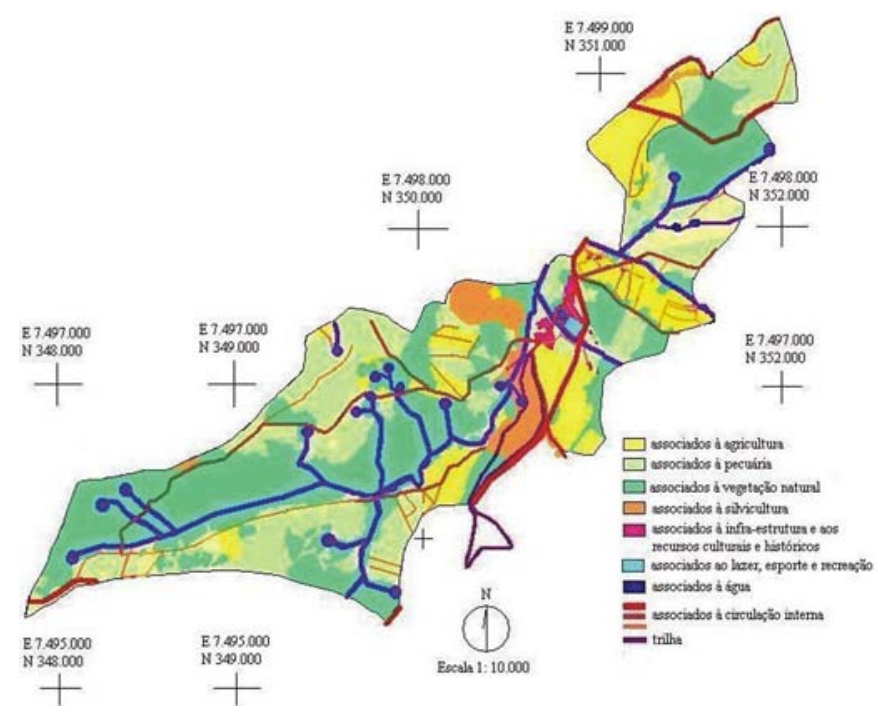

Figura 3. Classes de capacidade de uso da terra (A), adequação de uso da terra (B) e categorias agroturísticas potenciais (C) da Fazenda Fartura 
abastecimento de água próprio, fossas sépticas, energia elétrica, mas sem atendimento mínimo de transporte público, sem coleta pública de lixo, reciclagem parcial e reaproveitamento da água proveniente do processamento do café.

A diversidade observada pode conduzir à conclusão de que há uma paisagem rural estética, composta de patrimônio natural e cultural, o que propicia o desenvolvimento do agroturismo; ela responde, por exemplo, a todos os indicadores de diversidade da paisagem citados por Pires (2001) porém, além das áreas de fragilidade pelo uso agrícola já apresentadas, outros tipos de impacto foram observados na propriedade rural, tais como: linhas formadas por passagem dos animais, erosão de morros e compactação do solo causada pelo pisoteio do gado; pisoteio humano nas áreas naturais (trilhas) para ter acesso às cachoeiras, gruta e rios; erosão do solo causada por um desvio de curso d'água natural; presença de áreas com solo exposto destinadas ao cultivo podendo favorecer a ocorrência de processos erosivos ou a presença de elementos intrusivos à paisagem (por exemplo, as linhas de transmissão de energia elétrica).

Obteve-se, a partir do grupo dos indicadores turísticos, o mapa de categorias agroturísticas, produto intermediário que agrupa os principais atributos existentes na fazenda em diferentes categorias de entretenimento ou atrativos alinhados a projetos de agroturismo; este mapa associou as informações sobre cobertura vegetal, agricultura, pecuária, silvicultura, presença de água, esporte, lazer e recreação, infraestrutura, recursos históricos e circulação interna da propriedade, como resumem a Figura 3C e a Tabela 5.

Tabela 5. Área percentual aproximada ocupada pelas categorias agroturísticas potenciais existentes na Fazenda Fartura

\begin{tabular}{lc}
\hline Categorias de entretenimentos agroturísticos & Área percentual (\%) \\
Associados à vegetação natural & 40 \\
Associados à agricultura & 13 \\
Associados à pecuária & 30 \\
Associados à silvicultura & 6 \\
Associados à água & 7 \\
Associados a infraestrutura e recursos culturais e históricos & \\
Associados ao lazer, esporte e recreação & 4 \\
Associados à circulação interna & \\
\hline
\end{tabular}

Notou-se que os entretenimentos agrupados em categorias passíveis de serem desenvolvidos em associação com a cobertura vegetal natural, a agricultura e a pecuária, representam o potencial mais expressivo na propriedade, se considerados em termos percentuais ou de extensão em área ocupada; assim, essas 3 categorias, somadas, ampliam as chances de implementação do agroturismo ou atividades ligadas à agricultura.

De acordo com as categorias agroturísticas, podem ser criados os circuitos temáticos de visitação dentro da fazenda, de forma integrada, percorrendo os melhores pontos atrativos apropriados à finalidade agroturística. É preciso considerar que as atividades agroturísticas podem levar a mudanças no uso da terra e deterioração da paisagem causadas pelo aumento do fluxo de pessoas e por suas ações. $\mathrm{O}$ prévio conhecimento dos impactos possíveis advindos de atividades agroturísticas, pode facilitar a elaboração de projetos ambientalmente adequados para a propriedade rural.

A avaliação global da potencialidade agroturística da Fazenda Fartura resultante da aplicação dos parâmetros de ponderação dos indicadores ambientais, agropecuários e turísticos locais, conforme descrito no procedimento metodológico, é apresentada na Tabela 6.

Por meio da avaliação dos conjuntos de indicadores ficou evidenciado que, em relação ao aspecto turístico, a fazenda apresentou os melhores recursos, os quais confirmaram a sua qualificação para a visitação turística sob diferentes modalidades, apesar da falta de infraestrutura de hospedagem. Para composição do potencial ambiental, o segundo em importância na fazenda contribuiu, em maior proporção, com a cobertura vegetal.

Quanto ao potencial associado às explorações agrícolas e pecuárias, um atributo essencial para o agroturismo, a fazenda obteve a menor pontuação apesar de apresentar atributos muito favoráveis, como a diversidade de uso agrossilvopastoril e a aplicação de práticas de manejo e conservação do solo. O principal aspecto desfavorável responsável pela redução do potencial agropecuário local recaiu sobre fatores como a fragilidade de uso da terra, oriunda da ocorrência simultânea de áreas de alta declividade e uso agrícola incompatível com a capacidade de uso.

Referente ao potencial ambiental, o principal fator limitante e que o distanciou da condição ideal, foi a declividade local, uma vez que na propriedade predominam os terrenos com declives entre 12 e $43 \%$. A alternativa para a utilização dessas terras exige, necessariamente, manejo racional e planejamento cuidadoso do uso e ocupação, incluindo-se as atividades turísticas rurais.

Em suma, a condição ideal, em termos de potencial global, estaria condicionada à presença de todos os atributos indicadores (ambientais, agropecuários e turísticos) em sua expressão (valor) máxima; entretanto, como constatado, em função de fatores desfavoráveis ou limitantes a fazenda apresentou condição de potencialidade ao agroturismo distante

Tabela 6. Pontuação da propriedade rural em relação aos indicadores locais de potencialidade ao agroturismo e respectivos percentuais

\begin{tabular}{ccccccc}
\hline $\begin{array}{c}\text { Grupos de } \\
\text { indicadores }\end{array}$ & $\begin{array}{c}\text { Pontuação da } \\
\text { propriedade em } \\
\text { relação aos grupos correspondente (\%) } \\
\text { de indicadores }\end{array}$ & $\begin{array}{c}\text { Pontuação ideal em } \\
\text { relação aos grupos } \\
\text { de indicadores }\end{array}$ & $\begin{array}{c}\text { Percentual de } \\
\text { afastamento da } \\
\text { condição ideal (\%) }\end{array}$ & $\begin{array}{c}\text { Pontuação da } \\
\text { propriedade em } \\
\text { relação ao conjunto } \\
\text { de indicadores } \\
\text { (global) }\end{array}$ & $\begin{array}{c}\text { Pontuaçãa global } \\
\text { ideal }\end{array}$ & $\begin{array}{c}\text { Média percentual } \\
\text { da pontuação } \\
\text { global da } \\
\text { propriedade em } \\
\text { relação à ideal (\%) }\end{array}$ \\
Ambientais & 86 & 73 & 117 & 27 & 446 & 579 \\
Agropecuários & 134 & 72 & 186 & 28 & & 77 \\
Turísticos & 226 & 82 & 276 & 18 & & \\
\hline
\end{tabular}


aproximadamente $23 \%$ da condição ideal ou de máxima potencialidade. Para se alcançar maior proximidade à condição de plena potencialidade agroturística, poder-se ia investir esforços em determinadas ações locais como, por exemplo, no aspecto agrícola: priorizar a prática de medidas alternativas de utilização da terra optando por substituir cultivos temporários por outros semi-perenes ou permanentes e incentivar a visitação agroturística nos locais em que o uso agrícola é adequado e onde existe menor risco de erosão.

Pelos resultados descritos e conferidos em campo podese afirmar que a estratégia permite avaliar o nível de proximidade da situação ideal de conservação, turismo e agroturismo de uma propriedade rural voltada à visitação pública e auxiliar a tomada de decisão em direção a um planejamento mais adequado da atividade, identificando os espaços de maior potencialidade, global ou temática, para o agroturismo. O procedimento metodológico permitiu reconhecer os elementos de campo que merecem maior empenho para o manejo indicando o caminho para a aplicação de alternativas ambientalmente integradas, com maiores chances de sucesso e, ao mesmo tempo, assegurando a conservação ambiental e sustentabilidade do empreendimento.

Acredita-se que a maior crítica à estratégia proposta está relacionada à pontuação dos indicadores, que lhe foi atribuída de forma subjetiva. É uma leitura e um recorte pessoal da literatura, podendo ter diferentes resultados se elaborada por outros autores; além disso, nem todos os indicadores citados como relevantes serviram efetivamente para diferenciar a potencialidade da área de estudo, pois são globais para a área, como no caso, por exemplo, dos indicadores relacionados à infraestrutura de recepção e hospedagem e infraestrutura física e social. Desta forma, trabalhos futuros poderiam minimizar a quantidade de atributos analisados, concentrando os levantamentos nos indicadores que se mostraram de maior expressividade, como por exemplo: a atividade agrossilvopastoril, a cobertura vegetal, os recursos hídricos, a qualidade da paisagem, as vias de acesso e o patrimônio cutural arquitetônico. Outra provável crítica ao estudo se refere ao fato de que apenas a diversidade de atributos existentes e potenciais foi considerada e não sua extensão no terreno; neste caso se assumiu que qualquer atividade planejada pode ser desenvolvida em pequenos locais. Por outro lado, a estratégia permite o controle da importância dada pelo executor e a espacialização do potencial e impactos sobre o terreno sob a perspectiva do meio físico-biótico.

\section{CONCLUSÕES}

1. A estratégia metodológica desenvolvida nesta pesquisa permite, efetivamente, orientar o planejamento de atividade agroturística ligado à questão da conservação ambiental e integrado às outras tipologias de turismo que ocorrem no espaço rural.

2. A interpretação dos indicadores inventariados em três diferentes grupos, referentes às temáticas ligadas aos interesses ambientais, agropecuários e turísticos, foi uma estratégia válida que facilitou a organização, a ponderação, a hierarquização e a avaliação somada dos atributos da propriedade.
3. A organização dos dados permitiu segmentar as limitações das potencialidades de uma propriedade rural frente à possibilidade de se instalar atividades agroturísticas.

4. Os indicadores declividade e fragilidades de uso do solo foram, pela objetividade das medidas, os que melhor serviram para apontar as limitações locais para o agroturismo.

\section{AGRADECIMENTOS}

Às agências financiadoras representadas pela Coordenação de Aperfeiçoamento de Pessoal de Nível Superior CAPES, e pelo Conselho Nacional de Desenvolvimento Científico e Tecnológico - CNPq - Brasil, que possibilitaram a realização deste trabalho de pesquisa.

\section{LITERATURA CITADA}

AIAB - Associazione Italiana per l'Agricoltura Biologica - Formazione Eco-Turismo. Progetto Leonardo. 2000. <http:// www.aiab.it/agriturismi>. 07 Ago.2003.

Campanhola, C.; Silva, G. da. Desenvolvimento local e a democratização dos espaços rurais. Cadernos de Ciência e Tecnologia, v.17, n.1, p.11-40, 2000.

Cox, L. J.; Fox, M. Agriculturally based leisure attractions. The Journal of Tourism Studies, v.14, n.1, p.49-58, 2003.

Ferrão, A. M. de A. Arquitetura rural e o espaço não urbano. Labor \& Engenho: Patrimônio Cultural. v.1, n.1, p.89-110, 2007.

Kuo, N. W; Chiu, Y. T. The assessment of agritourism policy based on SEA combination with HIA. Land Use Policy, v.23, n.4, p.560-570, 2006.

Lepsch, I. F. Formação e conservação dos solos. 1.ed. São Paulo: Oficina de Textos, 2002. v.1. 178p.

Oliver, T.; Jenkins, T. Sustaining rural landscapes: The role of integrated tourism. Landscape Research, v.28, n.3, p.293-307, 2003.

Pedreira, B. da C. C. G. Seleção de espaços rurais para desenvolvimento do agroturismo sob a perspectiva da conservação ambiental: Uma proposta metodológica. Campinas: UNICAMP, 2006. 343p. Tese Doutorado

Pires, P. S. A paisagem rural como recurso turístico. In: Turismo rural: Práticas e perspectivas. Rodrigues, A. B. (org.). Coleção turismo contexto. São Paulo: Contexto. 2001. p.117-132.

Rocha, J. V.; Lamparelli, R. C.; Weill, M. A. Diagnóstico do meio físico e estabelecimento de diretrizes para controle e prevenção da erosão na Bacia do Rio Mogi-Guaçu. Campinas: UNICAMP, 2000. 81p. Relatório Técnico Final. GEO-Grupo de Estudos de Geoprocessamento.

Salvati, S. S. Turismo rural e certificação: Qualidade e responsabilidade no campo. In: Congresso Brasileiro de Turismo Rural, 4, 2003, Piracicaba. Anais... Campinas: FEALQ, 2003. p.87-94.

Santos K. S.; Gomes, R. A. Gestão ambiental como estratégia para a competitividade da atividade turística no espaço rural. In: Congresso Brasileiro de Turismo Rural, 4, 2003, Piracicaba. Anais... Campinas: FEALQ, 2003. p.385-390.

Vezzani, M. A. Turismo rural e responsabilidade ambiental e ecológica no espaço rural brasileiro. Caderno Virtual de Turismo, v.8, n.1, p.27-39, 2008. 